CrossMark \& click for updates

Cite this: Chem. Commun., 2015, 51, 10576

Received 3rd April 2015,

Accepted 29th May 2015

DOI: $10.1039 / c 5 c c 02793 d$

www.rsc.org/chemcomm

\title{
Recent advances in the development of synthetic chemical probes for glycosidase enzymes
}

\begin{abstract}
Helen M. Burke, Thorfinnur Gunnlaugsson* and Eoin M. Scanlan*
The emergence of synthetic glycoconjugates as chemical probes for the detection of glycosidase enzymes has resulted in the development of a range of useful chemical tools with applications in glycobiology, biotechnology, medical and industrial research. Critical to the function of these probes is the preparation of substrates containing a glycosidic linkage that when activated by a specific enzyme or group of enzymes, irreversibly releases a reporter molecule that can be detected. Starting from the earliest examples of colourimetric probes, increasingly sensitive and sophisticated substrates have been reported. In this review we present an overview of the recent advances in this field, covering an array of strategies including chromogenic and fluorogenic substrates, lanthanide complexes, gels and nanoparticles. The applications of these substrates for the detection of various glycosidases and the scope and limitations for each approach are discussed.
\end{abstract}

\section{Introduction}

The objective of this review is to provide a comprehensive overview of the enzyme activated, synthetic probes that have been developed for the detection of glycosidase enzymes. Glycosylation is one of the most important post-translational modifications of proteins and it is estimated that over $50 \%$ of

School of Chemistry and Trinity Biomedical Sciences Institute, Trinity College, Pearse St, Dublin 2, Ireland. E-mail: gunnlaut@tcd.ie, eoin.scanlan@tcd.ie; Fax: +3531716 2628; Tel: +35318963459 human proteins are glycosylated. ${ }^{1}$ Carbohydrates are often displayed in the form of glycoconjugates such as glycoproteins, proteoglycans and glycosphingolipids. They are ubiquitous in nature and play a pivotal role in a diverse range of biological processes including fertilisation, neuronal development, hormone activities and inflammatory responses. ${ }^{2-4}$ Metabolism of glycans is therefore critical to the biological function of a given organism. Degradation of carbohydrates and glycoconjugates is challenging due to the stability of glycosidic linkages. ${ }^{5}$ In nature, the hydrolysis of glycosidic linkages is catalysed by a

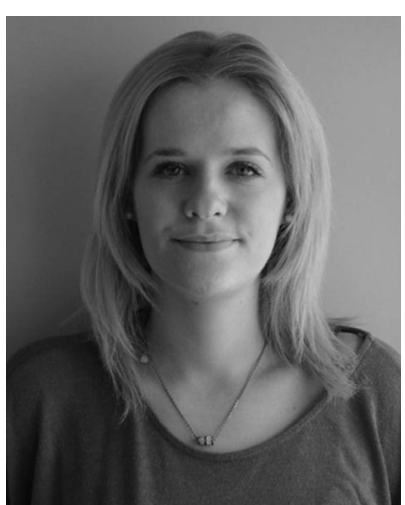

Helen M. Burke
Helen Burke graduated from Trinity College Dublin in 2012 with a degree in Medicinal Chemistry. During her undergraduate studies, she was selected to participate in the Summer Undergraduate Research Experience (SURE) in Trinity College under the supervision of $\mathrm{Dr}$ Enda Bergin where she carried out research in the area of catalysis. She is currently undertaking her PhD under the joint supervision of Prof. Eoin Scanlan and Prof. Thorri Gunnlaugsson after being awarded an IRCSET Embark Scholarship. Her current projects involve the design and synthesis of lanthanide-based sensors for the detection of glycosidase enzymes and novel methodology for the specific $N$-glycosylation of proteins.

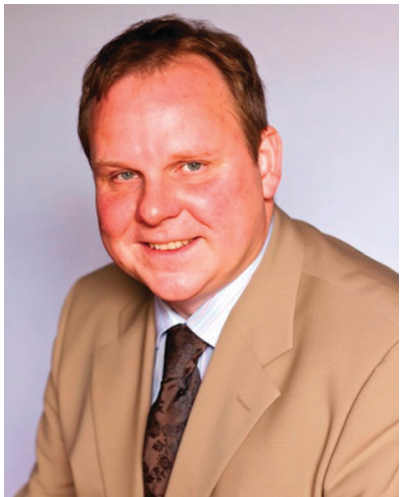

Thorfinnur Gunnlaugsson
Thorri Gunnlaugsson MRIA holds a Personal Chair in the School of Chemistry at Trinity College Dublin as Professor of Chemistry, and is a $P I$ in the Trinity Biomedical Sciences Institute. His research focuses on the areas of supramolecular, materials and medicinal chemistry, having published over 180 papers to date. $\mathrm{He}$ was the recipient of the RSC Bob Hay Award (Lecture) in 2008 and in 2011 he was elected a Member of the Royal Irish Academy. In 2014 he was awarded The Institute of Chemistry of Ireland (ICI) Annual Award for Chemistry (Eva Philbin Lecture) for his contribution to the field. 
class of enzymes known as glycosidases. These enzymes increase the rate of hydrolysis by $10^{17}$ fold when compared to spontaneous hydrolysis events and exhibit exquisite substrate selectivity. ${ }^{6}$ This remarkable acceleration in rate identifies glycosidases as highly efficient catalysts for this process. Despite the fact that all the glycosidase enzymes catalyse similar reactions, approximately $3 \%$ of the human genome is dedicated to the encoding of these enzymes.

The large number of glycosidases found in nature has led to their classification into various categories based on criteria such as catalytic mechanism, substrate specificity, site of glycosidic bond cleavage and amino acid sequence. ${ }^{7,8}$ Glycosidases are referred to as exo, if they specifically act on the termini of polysaccharides, while endo-glycosidases promote internal hydrolysis of glycosidic linkages within a chain. The hydrolysis of the glycosidic bond can occur via one of two widely accepted mechanisms; proceeding with either retention or inversion of stereochemistry at the anomeric position, as outlined by Koshland in $1953 .^{9}$ In both cases, oxacarbenium ion intermediates and two amino acids (Asp or Glu) are involved in the mechanism. Several reports detailing the mechanism of action of the glycosidases on various carbohydrates have been published.,10,11 Glycosidases have been ordered into more than 120 different families based on amino acid sequence similarity and this classification has led to the generation of the CAZy database (available online at www. cazy.org). ${ }^{12-14}$ Glycosidases grouped within a particular family share structural similarities and often their hydrolytic mechanisms are the same. Due to the complex and varying roles of glycans in biology, glycosidases have been associated with a number of important biological processes and applications. ${ }^{15}$ Glycosidases have been reported to function as important gene markers, for example, the gene encoding $\beta \mathrm{Gal}$, lac $Z$, is extensively used as a reporter gene in animals and yeast. ${ }^{16} \mathrm{~A}$ popular reporter gene in plants is the $\beta$ Glu gene. ${ }^{17}$ Glycosidase enzymes are also known to

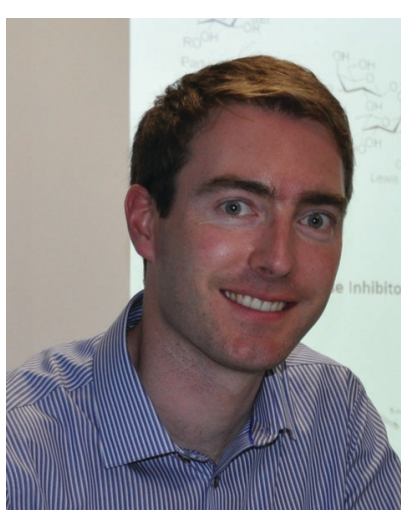

Eoin M. Scanlan
Eoin Scanlan graduated from the National University of Ireland, Galway in 2000. He completed his PhD in organic chemistry at the University of St. Andrews, UK, under the supervision of Prof. John Walton (2004). Following postdoctoral work with Prof. Philippe Renaud at the University of Bern, Switzerland and Prof. Benjamin Davis at the University of Oxford, UK, he started his independent academic career in Trinity College Dublin in 2008.

He is current Assistant Professor of Organic and Medicinal Chemistry and and is a PI in the Trinity Biomedical Sciences Institute. His research interests include synthetic carbohydrate chemistry and glycoconjugates, the development of novel synthetic methodology, functional materials and immunology.

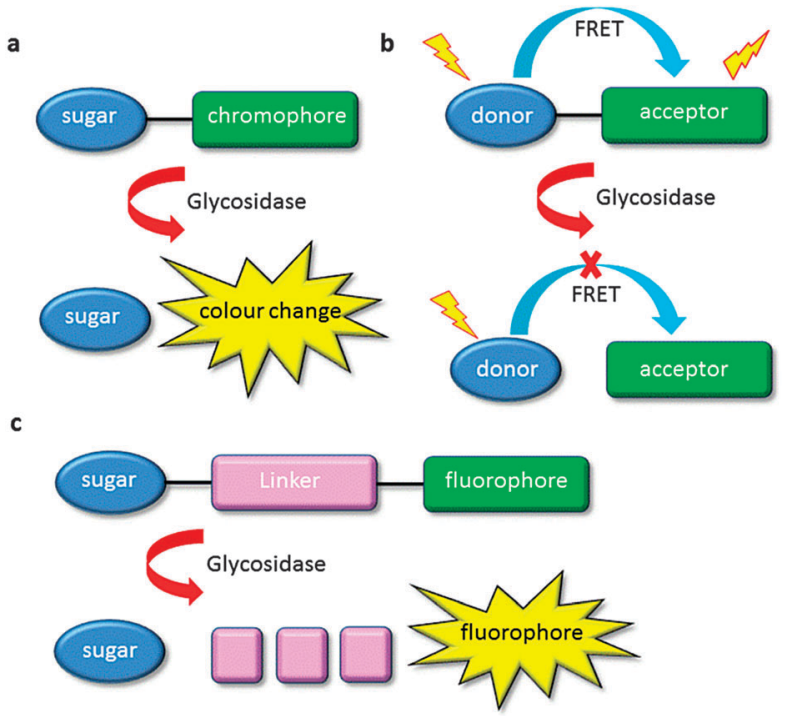

Scheme 1 Schematic illustration of (a) chromogenic-based reporters (b) distance-dependent FRET-based reporters (c) self-immolative activation of reporters; for glycosidase enzymes.

play a role in the pathology of several disease states. For example, aberrant glycosylation or glycosidase enzyme deficiencies are the marker for several pathological conditions including Gaucher and Parkinson's disease. ${ }^{18-23}$ Xylanases and cellulases are widely exploited in industry. Of particular interest is the application of cellulases for the industrial production of bio-ethanol. ${ }^{24}$ The realisation of glycosidases' dominant role in many biological and industrial processes has boosted research into the development of techniques to accurately detect and profile these enzymes so as to improve understanding of their function.

This review aims to survey the chemical tools developed to detect this important class of enzymes. The review will focus on chemical probes whereby a glycosidic linkage is hydrolysed and a reporter molecule is released. The review will not cover activity based glycosidase probes which have been comprehensively reviewed elsewhere. ${ }^{25}$ The bioactivatable probes presented herein cover the early chromogenic glycoside substrates which are widely used commercially and the various fluorogenic substrates starting from the early coumarin structures up to more recent FRET-based systems. Lanthanides as tools for probing glycosidase enzymes are described with an emphasis on the development in the field of MRI. Other approaches for glycosidase detection such as incorporation of substrates into gels or nanoparticles are described highlighting the vast array of probes available, each differing in their mechanism of signal generation as outlined in Scheme 1.

\section{Chromogenic substrates}

The simplest and most well established method for the detection of glycosidases is based on the liberation of a coloured product upon enzyme catalysed hydrolysis of a glycosidic linkage in a suitable glycoconjugate. Many such glycoconjugates are commercially available and this method allows visualisation 
by the naked eye. This approach does not require the use of specialised equipment, and can be applied in glycosidase inhibitor high-throughput screening (HTS). In an effort to increase the intensity of released chromophore, Richardson and Perry have screened various colourimetric substrates for glycosidases. $^{26,27}$ Glycoconjugates of $p$-nitrophenol ( $p$-NP) 1 were amongst the earliest chromogenic glycosidase substrates with the released nitrophenolate 2 displaying an intense yellow colour and absorbance at $405 \mathrm{~nm}$ (Fig. 1). The yellow colour of 2 is only visible at alkaline $\mathrm{pH}$ and its utility can be hampered when the absorbance of the inhibitor overlaps with that of 2 . However, this method is still widely used for the screening of glycosidase inhibitors and as a reference for the determination of absolute activities of enzyme samples. Wang and co-workers reported the novel amperometric detection of glycosidases based on $p$-NP glycosides. ${ }^{28}$ The anodic signal arising from the subsequent electro oxidation of the released $p$-NP was determined to be directly proportional to the activity of the enzyme.

Indoxyl glycosides are powerful chromogenic substrates used in histochemistry, biochemistry and bacteriology. ${ }^{29}$ Hydrolysis of the glycosidic bond releases a reactive indoxyl which is oxidised, under aerobic conditions, to produce an insoluble dimeric blue indigoid dye 4 (Fig. 1). The indoxyl group may be decorated with halides with the variation of the substitution patterns determining the colour. ${ }^{30}$ The most commonly used substrate is 5-bromo-4-chloro-3-indolyl-beta-Dgalactopyranoside (X-Gal), 3 which is routinely applied to microbial cultures, however indigoid dyes tend to be insoluble in water thus requiring the addition of organic solvents which may partially inhibit enzyme activity. ${ }^{29}$ The widespread utility of these dyes has been hampered by the challenging and low yielding synthesis of indoxyl glycoside derivatives, however recent reports by Thiem et al. have described improved synthetic approaches. ${ }^{31,32}$ Maeda and co-workers have reported a novel assay using 3 as a substrate. ${ }^{33}$ The $\mathrm{H}_{2} \mathrm{O}_{2}$ produced during the oxidation of the indoxyl reacts with residual 3 in the presence of horseradish peroxidase (HRP) to emit light, resulting in a novel chemiluminescent assay for detection of glycosidases. Colourimetric assays based on gold nanoparticles (AuNPs) have also been reported for the glycosidase enzymes (see Section 5.2). Furthermore, Ruan et al. reported that the formation of blue indigoid dye can be used for alkaline phosphatase enzyme assays using SERRS as a technique (see Section 5.3). ${ }^{34}$

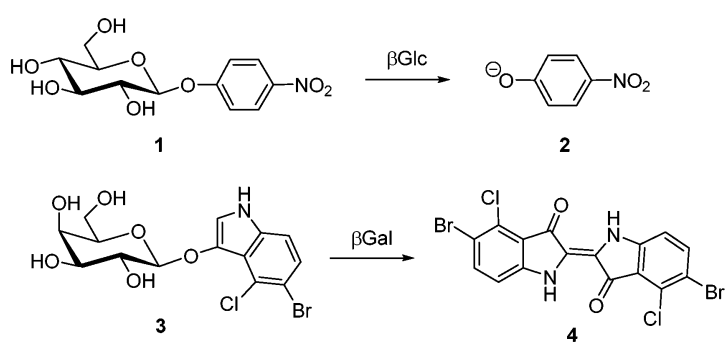

Fig. 1 Examples of chromogenic enzyme substrates.

\section{Fluorogenic substrates}

Fluorescence based measurements are several orders of magnitude more sensitive and tend to have lower limits of detection than colourimetric methods, thus can be used to detect enzymes at low concentration which is crucial for measurement in complex media. If carefully designed, fluorescent probes should exhibit negligible or no signal until they interact with their target enzyme allowing "on-off” switchability. To date, there has been a vast array of carbohydrate conjugated fluorophores reported with focus on umbelliferones, fluoresceins, and rhodamines, with each type having their own advantages depending on the particular application. Despite the wide array of fluorophores, fluorescent probes are rarely used in a clinical setting as conventional probes absorb in the UV/Vis region which is problematic since this is where biomolecule absorption is high. Although, in recent years the focus has shifted to fluorophores with large stokes shifts and significant bathochromic shifts to allow for in vivo studies. ${ }^{35}$

\subsection{Coumarins}

Coumarins are a class of lactones comprising of fused benzene and $\alpha$-pyrone rings (benzopyrones). They are widely used, small-molecule fluorophores due to their high fluorescence intensity, good cell permeation, ease of preparation, and excellent solubility. The electron-rich $\pi-\pi$ conjugated system imparts good charge-transport and fluorescent properties, rendering them excellent candidates for probing biologically-relevant species. ${ }^{36,37}$ Coumarin-based fluorescent probes have been developed for the detection of magnesium, ${ }^{38}$ zinc, ${ }^{39}$ elastase, ${ }^{40}$ thiophenols, ${ }^{41}$ and kinase enzymes. ${ }^{42}$ Dating back to the early 1950s, the coumarins of choice were the simple 4-methylumbelliferyl (4-MU) and resorufin derivatives, which were used as chemical probes for many different enzymes including esterases, phosphatases and glucosidases. ${ }^{43-45}$ Furthermore, 6,7-dihydroxycoumarin serves as a colourimetric assay for $\beta$ Glc due to enzymatic catalysed hydrolysis of the glycosidic linkage forming a brown-black complex in the presence of iron salts. ${ }^{27}$

In 1954, Mead and co-workers reported that glucuronides of umbelliferone were practically non-fluorescent whereas the corresponding hydrolysis products, hydroxycoumarins, were highly fluorescent at $\mathrm{pH}$ 10-11 and therefore could be used to determine $\beta$ Glc activity. ${ }^{46,47}$ Shortly thereafter, various derivatives of 4-MU were investigated as fluorogenic substrates for a range of glycosidase enzymes. ${ }^{47-49}$ The identification of sialidases using an umbelliferyl probe 5 was reported by Warner in 1975 (Fig. 2). ${ }^{50}$ This was followed by Schauer and co-workers ${ }^{51}$ who reported a 4-trifluoromethylumbelliferyl derivative 6 which served as a very sensitive substrate for eight different sialidases, overcoming the limitations of $\mathbf{5}$ as the $\mathrm{pH}$ did not have to be adjusted to $\mathrm{pH} 10$ to obtain full fluorescence (Fig. 2).

Mangan et al. reported a fluorometric cellulase assay based on a benzylidene protected $\beta$-cellotrioside, BzMUG3, using $4-\mathrm{MU}$ as the reporter group. The assay is selective for the endo-1,4- $\beta$-glucanase with the rate of 4 -MU formation being directly proportional to the enzyme activity. ${ }^{52}$ Zheng and co-workers ${ }^{53}$ 

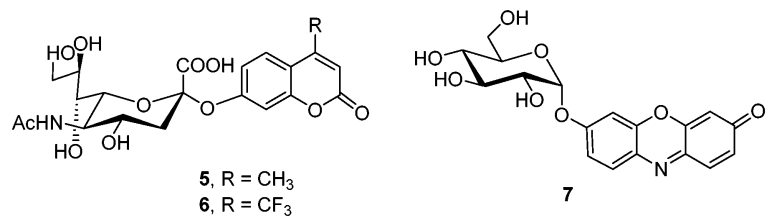

Fig. 2 Fluorogenic substrates based on the coumarin core structure.

reported resorufin- $\alpha$-D-glucopyranoside 7 as a substrate for $\beta$ Glc. This was superior to the previous assays developed which were based on the umbelliferone derivatives. This was followed by an $\alpha$ Gal derivative (Fig. 2). ${ }^{54}$ The emission of the product of the enzymatic reaction was red-shifted to $590 \mathrm{~nm}$ which reduced interference from background fluorescent compounds, as seen with 4-MU substrates..$^{55}$ Additionally, this allowed for continuous measurement of enzyme activity due to the lower $\mathrm{p} K_{\mathrm{a}}$ of the resorufin derivative, compared with 4-MU.

The use of coumarins for detection of glycosidases has been extended by Yang et al. who reported a novel platform $\mathbf{8}$ for the simultaneous measurement of both $\beta \mathrm{Glc}$ and phosphodiesterase activities, using 7-hydroxycoumarin as one of the fluorescent reporters (Fig. 3). ${ }^{56}$ Notably, interactions of each distinct enzyme produce a different signal readout based on either intramolecular PET or FRET processes.

FRET is a widely used phenomenon in the field of molecular biology. It is a non-radiative process involving energy transfer from an excited state donor to a ground state acceptor. The efficiency of FRET is highly dependent on the spectral overlap integral, the relative orientation of transition dipoles, and proximity of the donor and acceptor to each other. ${ }^{57-59}$ Extensive spectral overlap is displayed between coumarin emission and fluorescein excitation and this has been exploited for the design of FRET-based probes for enzymes. ${ }^{60}$ FRET-based assays have been used for the detection of glycosyltransferase activity but glycosidase sensing using FRET remains underdeveloped, despite the widespread utility such a technique would possess. ${ }^{61}$

PET is a well-known phenomenon through which the fluorescence of a fluorophore is quenched by electron transfer from a donor moiety to an acceptor moiety. ${ }^{62}$ PET systems traditionally exist in a 'fluorophore-spacer-receptor' format wherein electron transfer from the donor moiety quenches the

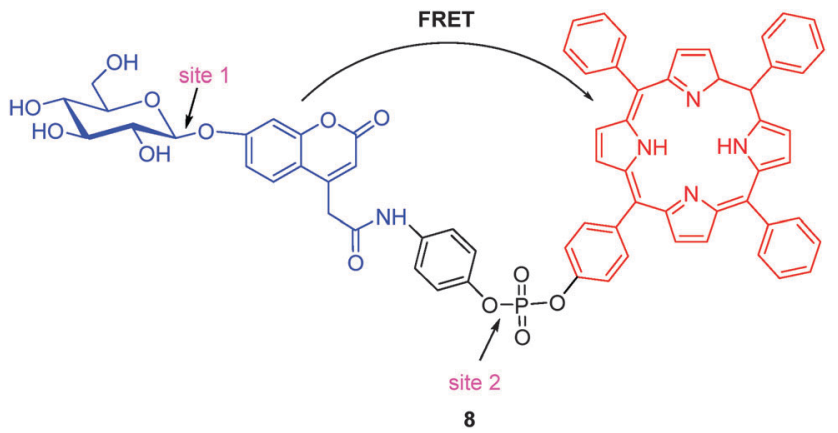

Fig. 3 FRET-PET system based on coumarin and TPP reporters showing dual sites for enzyme cleavage. ${ }^{56}$ acceptor in the "off" state. Binding of an analyte/enzymatic transformation restrains PET subsequently triggering an "on" state. ${ }^{62,63}$

The novel probe reported by Yang et al. possesses two enzyme cleavage sites and three separate fluorescent reporters with negligible cross-talk observed between them (Fig. 3). ${ }^{56}$ The applicability of the probe to image enzyme activity in liver cell lines was determined using fluorescence microscopy. Fluorescent images of cell lines clearly showed the separate donor and acceptor components, with endogenous $\beta$ Glc and phosphodiesterase activity producing blue and red fluorescence, respectively. Nagano utilised the spectral overlap of coumarin and fluorescein and a FRET-based approach to design a $\beta$ Gal labelling probe, CMFßGal, which can be monitored by changes in fluorescence. ${ }^{64}$

Withers and co-workers recently reported an elegant FRET probe using boron-dipyrromethane (BODIPY) and 7-hydroxycoumarin components to serve as the FRET acceptor and donor, respectively. ${ }^{65}$ This probe allowed for the monitoring of three key hydrolytic enzymes involved in ganglioside degradation. Notably, the probe is the first example reported to detect and localise human neuraminidase activity in living cells.

Shin reported the use of cocktails of simple coumarinconjugated compounds for the detection of glycosidase activity to generate activity profiles. ${ }^{66}$ This was carried out using HPLC analysis and by examining the pattern of product formation in the enzymatic reactions, further illustrating the use of coumarin derivatives in rapid detection of enzymatic activity. Coumarins have also been reported to sensitize lanthanide ions in analyteresponsive probes reported by Borbas (see Section 4.1). ${ }^{67,68}$

\subsection{Fluorescein}

Fluorescein, along with rhodamine, belong to the superfamily of xanthene dyes. Fluorescein is a widely used fluorophore due to its good water solubility and its visible excitation and emission. ${ }^{69,70}$ A widely exploited feature of fluorescein is the ability to switch between the non-fluorescent spirolactone and ring-opened forms. ${ }^{69}$ Thus, fluorescein probes can be utilised which are non-fluorescent until reaction with a target molecule occurs.

Fluorescein di- $\beta$-D-galactopyranoside (FDG) 9 is a highly sensitive substrate for $\beta \mathrm{Gal}$ and is commercially available (Fig. 4) ${ }^{71-73}$ Substrate 9 is hydrolysed in a sequential manner to release fluorescein whose fluorescence can be monitored at $514 \mathrm{~nm}$. The intermediate, fluorescein mono- $\beta$-D-galactopyranoside (FMG) 10, although a good substrate for $\beta$ Gal, has a strong fluorescence and absorbance at the wavelength used for detection of fluorescein thereby hampering its utility. ${ }^{74}$ Nolan et al. demonstrated that $\mathbf{9}$ could distinguish between lacZ+ and lac $\mathrm{Z}-$ cells using fluorescence-activated cell sorter (FACS) analysis. ${ }^{72}$ MacDonald reported use of $\mathbf{9}$ in a multiwell plate system, demonstrating the higher sensitivity of 9 compared with colourimetric $o$-NPG and fluorogenic 4-MU, although it was noted that the turnover rate is slower due to the requirement for sequential glycosidic bond hydrolysis. ${ }^{73}$ Moreover, fluorescein leakage from cells still remains a problem with 9 and the observed increase in fluorescence is known to be non-linear. Uttamchandani and co-workers have reported an $\alpha-N$-acetylgalactosamine containing quenched activitybased probe (qABP). A FACS analysis approach was used in directed 

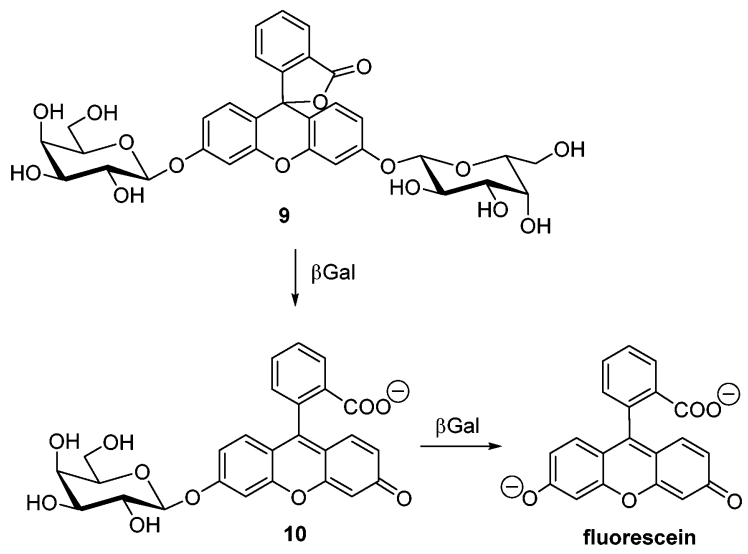

Fig. 4 Sequential FDG hydrolysis to yield fluorescein.

enzyme evolution experiments to identify an $\alpha-N$-acetylgalactosaminidase variant with enhanced catalytic activity. ${ }^{75}$

Nagano demonstrated that the fluorescein molecule could be viewed as a donor-acceptor PET system, where the benzene and xanthene moieties within the fluorescein chromophore act as the donor and acceptor respectively. ${ }^{62,76,77}$ Nagano substituted the carboxylic group of conventional fluorescein with a methyl moiety to generate a novel class of fluorescein molecules that displayed almost the same fluorescent properties and quantum yields as fluorescein, proving that the carboxylic group was not indispensable as previously reported. ${ }^{78}$ They reported the enzyme-responsive TG- $\beta$ Gal (Tokyo Green) 11, which was almost non-fluorescent with a small quantum yield until hydrolytic action of $\beta \mathrm{Gal}$ which afforded a highly fluorescent moiety, due to PET being restrained, which existed mainly in the anionic form under neutral $\mathrm{pH}$ conditions (Fig. 5). ${ }^{77}$ This probe has significant advantages over 9 in that it requires only a single hydrolytic step to release the fluorophore, thereby avoiding problems with moderately fluorescent 10. In addition a linear response is observed between fluorescence intensity and $\beta$ Gal activity. Furthermore, $\mathbf{9}$ is well known to be membrane impermeable whereas the lower hydrophilicity of 11 imparts cell-permeability allowing for real-time imaging of living cells. Due to the fluorescent product of $\mathbf{1 1}$ being readily washed out of cells, it is unsuitable for in vivo imaging. Hence, Nagano subsequently reported AM-TG- $\beta$ Gal 12 which is based on 11 but demonstrated improved intracellular retention and was therefore suitable for in vivo tumour imaging (Fig. 5). ${ }^{79}$ By introducing an acetoxymethyl ester, a dramatic fluorescence enhancement was observed upon addition of $\beta \mathrm{Gal}$ and subsequent intracellular hydrolysis by esterase enzymes generated a fluorescent molecule with a free carboxylate group which is not readily leaked from cells.

Nagano has further demonstrated the utility of fluorescein for enzymatic detection by reporting a fluorescein analogue which fluoresces in the red region upon enzymatic hydrolysis. ${ }^{80}$ By replacing the oxygen at the 10-position of the xanthene unit in fluorescein with a $\mathrm{Si}$ atom, it was observed that deprotonation of the resulting phenolic substrate furnished a product $2 \mathrm{Me}-\mathrm{TM}$ 13 that red-shifted the absorbance by $110 \mathrm{~nm}$ relative to the
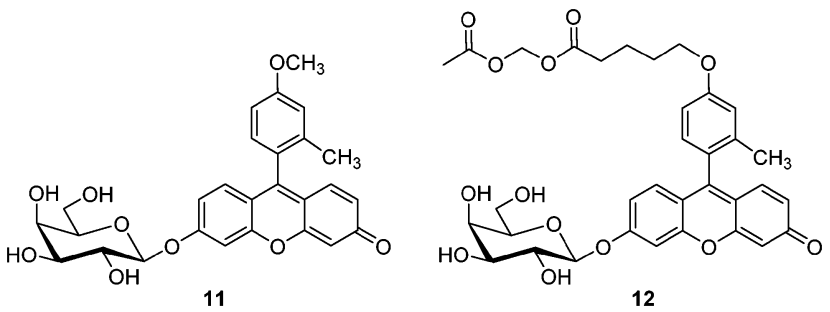

Fig. 5 Fluorescein derived PET substrates.

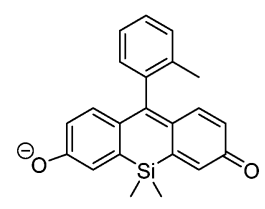

13



14
Fig. 6 Si-substituted fluorescein enzyme substrates developed by Nagano.

protonated form. This red shift is due to the difference in $\sigma^{*}-\pi^{*}$ conjugation between neutral and anionic forms. The related glycosylated substrate $2 \mathrm{Me}$-TM $\beta$-Gal 14 was prepared (Fig. 6).$^{80-82}$ Upon exposure of $\mathbf{1 4}$ to $\beta \mathrm{Gal}$, the expected dramatic red shift in the absorbance was observed and was accompanied by an increase in fluorescence intensity. A large fluorescence increase was also seen when 14 was incubated with lacZ+ cells, when excited at $580 \mathrm{~nm}$. This strategy of incorporating Si into xanthene dyes and the biological applicability has recently been reviewed by Nagano. ${ }^{83}$

\subsection{Rhodamine}

Rhodamine dyes have been one of the platform molecules for the design of fluorescent probes due to their high extinction coefficients, quantum yield, and photostability. ${ }^{84}$ In acidic media, rhodamine exists in a cationic form due to the carbonyl being protonated while a zwitterionic form is observed in basic solution due to dissociation. This negative charge induces a hypsochromic shift in the absorbance and fluorescence along with a reduction in extinction coefficient due to the inductive effect on the central carbon of the xanthene moiety. ${ }^{84}$ Analogous to fluoresceins, rhodamines are non-fluorescent when in the spirolactone form and strongly fluorescent when in a ring opened form. Furthermore, a key feature of rhodamines is that their fluorescence capabilities can be controlled by PET. ${ }^{69,84,85}$

In 2011, Nagano identified a rhodol derivative capable of serving as a probe for various hydrolases. ${ }^{86}$ Rhodol, being a hybrid of fluorescein and rhodamine, exhibits the desirable characteristics of rhodamine and fluorescein but displays less $\mathrm{pH}$-dependence making it an ideal candidate fluorophore. ${ }^{87,88}$ Moreover, as demonstrated by Nagano, conversion of the rhodamine carboxylate to a hydroxymethyl group induces spirocyclization and suppression of background fluorescence in an $O$-alkylated rhodol. Thus, due to the presence of a phenolic hydroxyl group in rhodol, it was used as a $\beta$ Gal probe, HMDER- $\beta$ Gal, 15 which is masked with a glycoside until enzyme activation triggers liberation of HMDER 16 and concomitant fluorescence enhancement occurs 
(Fig. 7). A 76-fold increase in fluorescence was observed upon addition of the enzyme and a clear in situ visualisation and co-localisation of $\mathbf{1 5}$ occurred with $\beta \mathrm{Gal}$ activity in Drosophila melanogaster. Furthermore, 15 displayed a $\log P$ and $\log D$ one unit larger than the previously reported fluorescein-based 11 suggesting it has improved cell permeability and in vitro applicability. ${ }^{77}$

Classic rhodamine dyes exhibit absorption and emission in the visible range, however, pioneering work by Nagano has led to the emergence of biologically applicable near-infrared (NIR) rhodamine dyes. It was reported that replacement of the oxygen atom in the xanthene ring with group 14 elements improves the fluorescent properties of classic rhodamines. A dramatic red-shift to NIR emission was observed due to the relatively low lying LUMO levels of the group 14 elements allowing the fluorescent properties to be readily controlled. ${ }^{89-91}$

Recent studies have been carried out by both Urano and Nagano in the area of enzyme-activated photosensitizers. The Nagano group reported $\beta \mathrm{Gal}$ activated photosensitizers based on thiazole orange, PhoTo-Gal, and fluorescein, TGI- $\beta$ Gal. ${ }^{92,93}$ However, these aforementioned probes were unable to induce targeted cell death. Replacing the oxygen atom at the 10-position of the xanthene moiety with a Se atom creates a more effective photosensitizer, as reported by Detty et $a l^{94}$ Thus, recently published work by both Urano and Nagano demonstrated the selective ablation of $\beta$-galactosidase-expressing cells by a Se-substituted rhodol derivative, HMDESeR- $\beta$ Gal 17, based on their previously reported 15 (Fig. 7). ${ }^{95,96}$ Incorporation of a galactosyl moiety into 18 suppresses phototoxicity, due to the presence of predominant spirocyclic xanthene form. Selective, enzyme-catalysed, glycosidic bond cleavage liberates phototoxic 18 which has the ability to produce ${ }^{1} \mathrm{O}_{2}$ upon irradiation at $532 \mathrm{~nm}$. Furthermore, ex vivo analysis of Drosophila showed that 18 induced cell death specifically in $\beta$-galactoside-expressing regions.

The Nagano group reported a series of hydroxymethyl rhodamine derivatives capable of detecting and visualising protease and glycosidase activity, on the basis of the spirocyclization capabilities of rhodamine. ${ }^{97}$ They found that the acetylated derivative of HMRG 19 existed in the closed form and was non-fluorescent due to loss of $\pi$-conjugation compared with phenolic 19 which was highly fluorescent and existed in the

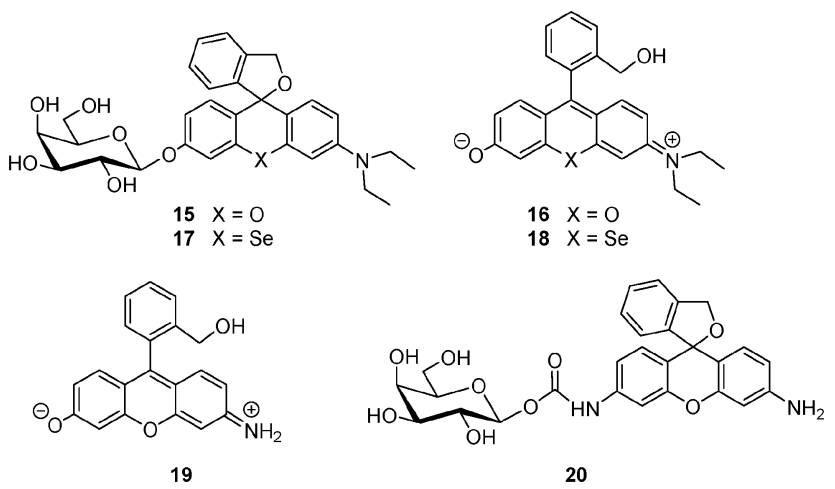

Fig. 7 Glycosidase activated rhodamine substrates. open form. Based on this observation, they incorporated enzyme specific substrate moieties in place of the acetyl group to form enzyme activated, fluorescent probes with "on-off" switchability. A galactose moiety was coupled to 19 via a carbamate linker to give $\beta$ Gal-HMRG 20 which exhibited no fluorescence until enzymatic action triggered the formation of the open form 19 with concomitant increase in fluorescence intensity (Fig. 7). Compound 20 was found to exhibit less background signal and improved fluorescence intensity, compared to the previously reported 15. ${ }^{96}$ Furthermore, 20 was also capable of visualising $\beta$ Gal activity in living cells. ${ }^{97}$

\subsection{Near-infrared emitting fluorophores}

NIR fluorophores have been the subject of intense research and development, but despite this, only a limited number of enzymatically-active NIR probes have been developed. The use of conventional fluorophores for in vivo applications is problematic due to high absorption of biomolecules in the UV/Vis region, easy scattering of visible light, and autofluorescence resulting in a low signal-to-noise ratio. ${ }^{35}$ Conversely, light in the NIR region is more suitable for in vivo applications as this represents the window where autofluorescence is at minimum resulting in a higher signal-to-noise ratio and deeper penetration into tissues. Extension of the $\pi-\pi$ conjugation system of conventional dyes is a common strategy for obtaining NIR fluorophores. Work by Renard and Hahn highlighted strategies for converting simple common dyes into water-soluble, photostable, far-red enzyme-activated fluorophores. ${ }^{98,99}$ Furthermore, a suitable in vivo probe must be endowed with a pharmacokinetic profile which allows it access to the native enzymes in order to provide a detectable signal. ${ }^{35,100,101}$

Weissleder and co-workers reported a far-red fluorescent probe for $\beta$ Gal, DDAOG 21, which displays a dramatic bathochromic shift of $50 \mathrm{~nm}$ upon hydrolysis to DDAO permitting product detection even in the presence of intact substrate 21 and more efficient tissue penetration (Fig. 8). ${ }^{102}$ The excitation and emission spectrums of hydrolysis product DDAO overlap to a large extent hampering its utility; nevertheless, the substrate was successfully employed for imaging of $\beta$ Gal expression in vivo. Gong and co-workers developed a protocol for the use of 21 in cultured cells highlighting the 12-fold higher signal-tobackground ratio of 21 compared to $o$-PNG. ${ }^{103}$ Compound 21 is commercially available and widely used in industry due to the

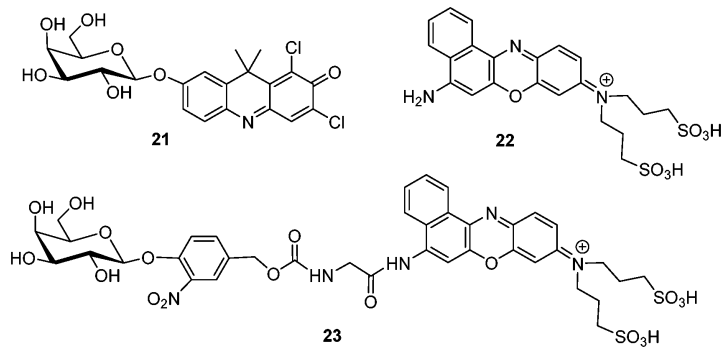

Fig. 8 NIR-based glycosidase substrate fluorophores. 
relatively low $\mathrm{p} K_{\mathrm{a}}$ of hydrolysis product, DDAO, allowing continuous monitoring of enzyme activity at physiological $\mathrm{pH}$.

Weissleder and Tung reported a new water-soluble, far-red fluorogenic molecule, 2SBPO 22 (Fig. 8). It was found that masking of the primary amino group of 22 resulted in a weak fluorescence and absorbance, which upon proteolytic cleavage generated a strong bathochromic fluorescence with a modest stokes shift. ${ }^{104,105}$ This observation was later used to generate a substrate for $\beta$ Gal detection, Gal-2SBPO 23 (Fig. 8). ${ }^{106}$ Although $\beta \mathrm{Gal}$ substrates are restricted to hydroxyl-linked fluorochromes, 22 was incorporated through a $p$-benzyloxycarbonyl moiety which is liberated via a self-immolative mechanism. Following enzymatic cleavage, $\mathbf{2 3}$ is hydrolysed to liberate $\mathbf{2 2}$ which can be followed by absorbance and fluorescence at $630 \mathrm{~nm}$ and $670 \mathrm{~nm}$, respectively. Additionally, the reaction can be followed by the liberation of 4-hydroxy-3-nitrobenzyl alcohol due to a yellow to blue colour change observed upon hydrolysis.

Recently, Tung and co-workers have developed a new NIR cyanine-based probe for detection and imaging of $\beta \mathrm{Gal}$, based on the previously reported fluorophore QCy7 24 (Fig. 9). ${ }^{107,108}$ GQCy7 25 has a structure similar to other cyanine dyes and functions by masking the phenol functional group and disrupting the $\pi$-electron system of the dye rendering it "off". Upon enzyme action, subsequent self-immolative elimination restores the conjugation of the system resulting in a 110-fold fluorescence increase of 24 emitting at $680 \mathrm{~nm}$. Compound 25 exhibited poor membrane permeability thus can only be used in cell-free assays. Conversely, the acetylated carbohydrate derivative, AcGQCy7, was found to be cell-permeable and was effectively retained in cells, thus proving suitable for $\beta \mathrm{Gal}$ imaging. The mechanism of intracellular fragmentation involves a thiol-dependent Michael addition followed by retro-Knoevenagel condensation to form a thionium ion which is subsequently hydrolysed by intracellular esterases and $\beta$ Gal to release fluorophore 26. However, 26 exhibits a dramatic hypsochromic shift to $560 \mathrm{~nm}$ which diminishes the potential application of AcGQCy7 for in vivo studies.

Squarine dyes exhibit desirable, long wavelength absorption and high extinction coefficients rendering them useful candidates for NIR applications. ${ }^{109}$ Nagano and co-workers reported a novel design strategy for NIR probes based on a squarylium scaffold 6SqGal 27 to visualise $\beta$ Gal activity (Fig. 10). ${ }^{110}$ Based on the fact that polymethine dyes exhibit fluorescence enhancement and a dramatic red shift in their emission upon interaction with



Fig. 9 Self-immolative NIR glycosidase substrates.

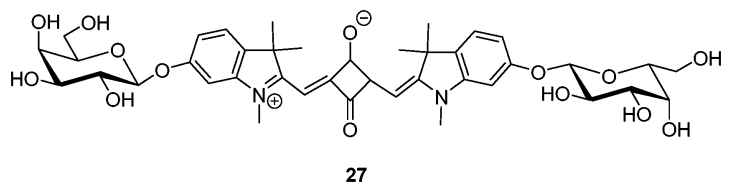

Fig. 10 Squarine-based 6SqGal 27.

serum proteins, it was proposed that the introduction of an enzyme-active functional group into the dye could suppress these interactions. Selective cleavage of the glycosidic bond triggers a dye-protein interaction accompanied by a fluorescence enhancement. ${ }^{110-112}$ The squarylium hydrolysis product of $27,6 \mathrm{SqOH}$, displayed a significant spectral change upon enzymatic action and subsequent protein interaction. Moreover, 27 exhibited a binding parameter of two orders of magnitude lower than hydrolysis product $6 \mathrm{SqOH}$ confirming that the glycan moiety suppresses the protein-dye binding affinity. Bright fluorescent images and notable subcellular localisation of 27 in lacZ+ cells was observed. Furthermore, the ability of 27 to image $\beta \mathrm{Gal}$ activity in vivo in mice was demonstrated with the enhancement of fluorescence intensity of a targeted $\beta$ Gal-encoding liver plasmid clearly visible.

Vocadlo and co-workers reported a glucocerebrosidase (GCase) substrate $\mathbf{2 8}$ which is a fluorescence-quenched substrate before enzyme action (Fig. 11). ${ }^{113}$ Substrate 28 showed localisation within the lysosome and allowed the timedependent monitoring of endogenous GCase activity within human fibroblasts. Substrate $\mathbf{2 8}$ contains the quencher group Black Hole Quencher 2 (BHQ2) attached to the anomeric center using a spacer and the fluorophore BODIPY attached to the 6-position as modification at this position has been reported to be tolerated. ${ }^{114}$ When intact, 28 is effectively quenched but upon hydrolytic cleavage NIR fluorescence is observed. Compound 28 shows excitation and emission at $574 \mathrm{~nm}$ and $595 \mathrm{~nm}$, respectively, and an impressive 99.9\% quenching efficiency producing a probe with good dark-to-light switchability. Furthermore, live cell imaging in human fibroblasts was

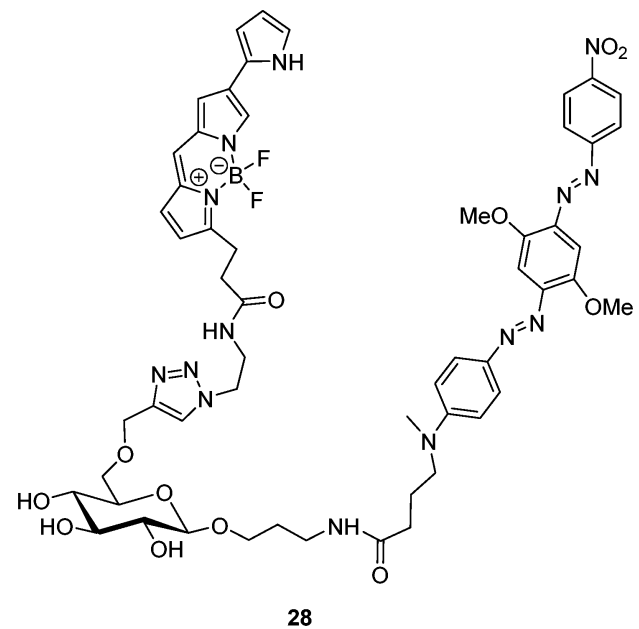

Fig. 11 Fluorescence quenched GCase substrate. 
demonstrated and the fluorescence increase proved to be time and dose-dependent while exhibiting no cytotoxicity.

\section{Lanthanide ions}

The intricate optical and spectroscopic properties of the lanthanides ions make them useful spectroscopic tools for probing biological processes. The lanthanides exhibit sharp, narrow bands in their emission spectra and a large pseudo Stokes shift. ${ }^{115}$ Perhaps the most useful property of the $\operatorname{Ln}(\mathrm{III})$ ions is their long-lived excited states, in the millisecond range, owing to the parity-forbidden $\mathrm{f}-\mathrm{f}$ transitions. ${ }^{116,117}$ This allows for the implementation of time-resolved luminescence measurements where there is a delay between the excitation and measurement of emission, obviating problems with autofluorescence. ${ }^{118,119}$ Due to the Laporte forbidden nature of the $\mathrm{f}-\mathrm{f}$ transitions, the $\mathrm{Ln}(\mathrm{III})$ ions have inherently low molar absorption coefficients making direct excitation of the $\mathrm{Ln}$ (III) problematic. This is overcome by the incorporation of an appropriate chromophore into the $\operatorname{Ln}(\mathrm{III})$ complex to allow "indirect sensitisation" of the $\operatorname{Ln}(\mathrm{III})$ ion. Furthermore, the high coordination requirements of the Ln(III) ions must be fulfilled due to their inherent toxicity. ${ }^{118,120,121}$

One of the most commonly used ligand frameworks for lanthanide complexation is cyclen (1,4,7,10-tetraazacyclododecane). ${ }^{122}$ Structurally diverse complexes based on the cyclen framework can be designed and constructed through the alteration of the pendant arms resulting in an architecture endowed with high kinetic and thermodynamic stability. Given their potential utility, there has been a recent surge of interest in the chemistry of the lanthanides. A huge array of diverse applications have been reported including their role in the formation of Langmuir-Blodgett films, ${ }^{123,124}$ in the sensing of biologically relevant anions and metal ions, ${ }^{125-130}$ and in the determination of 3D protein-ligand complexes due to their prominent use as shift reagents in NMR spectroscopy. ${ }^{131,132}$ Moreover, luminescence measurements represent a facile, non-invasive method to monitor enzymatic reactions. ${ }^{133,134}$

\subsection{Probes based on lanthanide luminescence}

Borbas and co-workers reported a series of novel analyteresponsive luminescent probe capable of detecting $\mathrm{H}_{2} \mathrm{O}_{2}, \mathrm{Pd}^{0 / 2+}$, $\mathrm{F}^{-}$and $\beta \mathrm{Gal}$ by alternating the analyte-responsive moiety. ${ }^{67}$ They previously demonstrated that coumarins sensitise $\mathrm{Tb}(\mathrm{III})$ and $\mathrm{Eu}(\mathrm{III})$ ions efficiently and applied this concept to develop a nonsensitising precursor 29, based on a $\mathrm{Ln}$ (III)-cyclen framework that undergoes a chemoselective reaction upon analyte activation to generate a coumarin sensitizer 30 (Fig. 12). ${ }^{135}$ Additionally, it was shown that $\beta \mathrm{Gal}$ activity could be monitored in cells expressing lac $Z+$ in real-time, resulting in intense Eu(III)-centred emission.

This antenna-triggered sensitisation strategy was later elegantly employed by Borbas to produce a multiple analyte detection system. ${ }^{68}$ A method was developed using varying lanthanide-based probes with different emission wavelengths that allowed a multi-colour detection method. The activity of $\beta$ Gal and alkaline phosphatase was simultaneously monitored

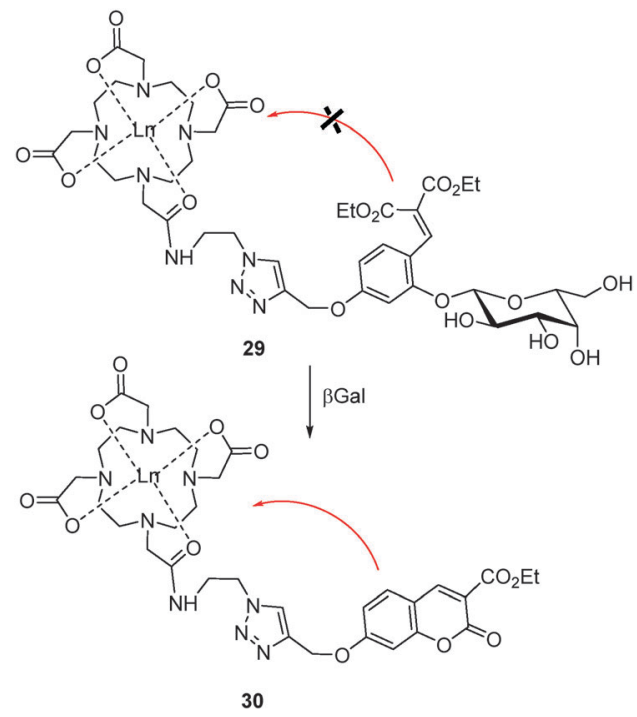

Fig. 12 Glycosidase triggered lanthanide antennae formation.

following emission at $545 \mathrm{~nm}$ and $655 \mathrm{~nm}$ for $\mathrm{Tb}(\mathrm{III})$ and $\mathrm{Eu}(\mathrm{III})$, respectively, with no spectral cross-talk observed between the emitters. Furthermore, the feasibility of a three-colour detection system was demonstrated using a coumarin-based organic fluorophore, whose absorption and emission is outside the range of the two lanthanide emitters. Thus, three non-interacting analytes; $\beta \mathrm{Gal}$, alkaline phosphatase, and $\mathrm{H}_{2} \mathrm{O}_{2}$ were monitored at 450, 545, and $655 \mathrm{~nm}$, respectively.

\subsection{Probes based on lanthanide relaxivity}

The work of enzyme-responsive MRI contrast agents was pioneered by Meade and co-workers, with the development of the first bio-responsive $q$-modulated contrast agent, Egad 31 (Fig. 13). ${ }^{136}$ NMR relaxivity of the galactose-substituted Gd(III)cyclen complex was selectively "switched-on" by removal of the galactopyranoside with $\beta \mathrm{Gal}$. Exposure to $\beta \mathrm{Gal}$ causes the transition from a weak to a strong relaxivity state by affecting the ability of galactopyranose to modulate the rate of water exchange at the Gd(III) centre. This was confirmed through recording the exponential decay of luminescence of a $\mathrm{Tb}$ (III) derivative to determine the hydration number, $q$, which confirmed a $40 \%$ increase in the number of inner sphere water
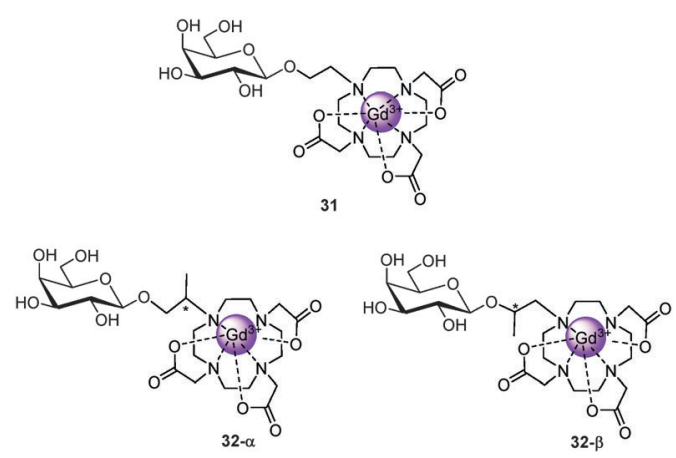

Fig. 13 "Smart" enzyme-responsive MRI contrast agents. 
molecules, upon hydrolysis of the glycosidic bond. Additionally, this change could be visualised in an MR image due to the $20 \%$ decrease in longitudinal relaxation time $\left(T_{1}\right)$ values accompanying enzymatic hydrolysis.

Complex 31 was further developed to improve its low relaxivity to allow for adequate in vivo imaging. The rigidity of 31 was increased through the introduction of an $\alpha$-methyl group limiting water access to the $\mathrm{Gd}(\mathrm{III})$ ion, generating EGadMe 32- $\alpha$ (Fig. 13). ${ }^{137}$ This modification caused a relaxivity change of 3 -fold upon enzymatic cleavage thus improving on the previously developed $\mathbf{3 1}$ and paved the way from more robust in vivo MRI imaging agents. Further mechanistic investigations were reported which demonstrated that varying substitutions patterns on the linker between the galactopyranose and cyclen had a profound effect on the MR image produced. $^{138}$ Structural isomers of EGadMe $32-\alpha$ and the mechanism for enzyme activation in both the presence and absence of carbonate was explored. It was determined that the position of the methyl group $(32-\alpha$ or $32-\beta)$ had a significant impact on the mechanism of water exclusion prior to enzymatic cleavage with the stereochemistry of the methyl group appearing to play no significant role. Substitution at the $\alpha$-position in 32- $\alpha$ allows for only outer-sphere contributions with the galactopyranose unit blocking water access whereas 32- $\beta$ displays dependence on carbonate concentration, suggesting that the sugar is not obstructing water access to the Gd(III) ion.

The enzyme kinetics of 32- $\alpha$ were not optimal, so in order to improve on this, Meade designed a new enzyme-activated agent 33 which operated via a self-immolative mechanism activated by $\beta$ Glc to furnish 34 (Fig. 14). ${ }^{139}$ The kinetics was quantified by the release of 4-hydroxy-3-nitrobenzyl alcohol $\left(\lambda_{\max }=422 \mathrm{~nm}\right)$. Complex 33 proved to be a better $\beta$ Glc substrate than the standard assay substrate, $p$-nitrophenyl- $\beta$-D-glucuronide.

Since the initial reports, detection of $\beta \mathrm{Gal}$ through "smart" MR contrast agents has been pursued by several groups. Nagano developed a receptor-induced magnetisation enhancement (RIME)-based $\beta$ Gal activated MRI contrast agent, 35 whereby increase in longitudinal water proton relaxivity $\left(r_{1}\right)$ occurs upon binding to a macromolecule, due to the slowing of molecular rotation (Fig. 15). ${ }^{140}$ Cleavage of the glycosidic bond

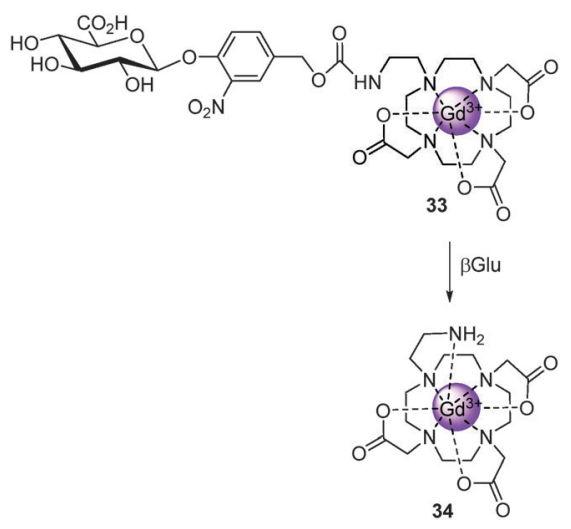

Fig. 14 Self-immolative $\beta$ Glu MRI contrast agent.
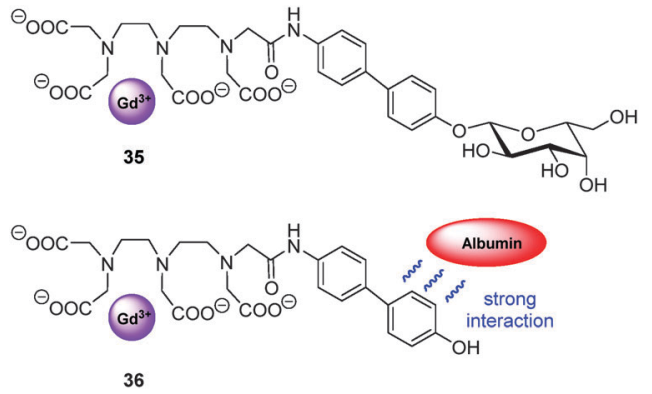

Fig. 15 RIME-based $\beta$ Gal activated MRI contrast agent.

of 35 releases a more hydrophobic aryl group 36, whose affinity for human serum albumin (HSA) is increased through a noncovalent interaction resulting in slower molecular tumbling and a strong relaxivity state.

Wang and Cheng reported a self-immolative Gd(III) contrast agent, Gd(DOTA-FPG) 37 whereby cleavage of the glycosidic bond by $\beta$ Gal caused an electron cascade, resulting in release of an electrophile which subsequently reacts with HSA to form a covalent adduct 38 (Fig. 16). ${ }^{141}$ A significant decrease in $T_{1}$ was observed in the presence of $\beta \mathrm{Gal}$ and HSA. Furthermore, the signal intensity was selectively increased in tumours with $\beta \mathrm{Gal}$ gene expression in vivo. However, it should be noted that HSA tends to reside inside extracellular compartments while $\beta \mathrm{Gal}$ is found in the cytoplasm which hampers the utility of methods reported by Wang and Nagano. Engelmann et al. tackled the problem of cell-permeation of MRI probes through the conjugation of peptide D-Tat ${ }_{49-57}$, in order to generate a cell-permeable, bimodal $\beta \mathrm{Gal}$ targeting agent. ${ }^{142}$ This peptide-conjugated Gd(III)-DOTA complex is only selectively cleaved and activated in $\beta$ Gal-containing cells.

In an effort to amplify the MRI response at targeted cells, Aime et al. published a Gd(III)-DOTA reporter which contained on its surface a $\beta$ Gal-tyrosine moiety, which was capable of reporting on $\beta \mathrm{Gal}$ expression in melanoma cells. ${ }^{143}$ Accumulation of a metal complex inside cells by the formation of oligopolymers had previously been reported by Bogdanov et al. ${ }^{144,145}$ Aime reported that following the action of $\beta \mathrm{Gal}$ and tyrosinase, melanin oligopolymers were formed accompanied by an increase in water proton relaxation rate and therefore a good relaxation enhancement effect. Also noteworthy, is the use of paraCEST (paramagnetic chemical exchange saturation transfer) for detecting enzymatic activity. The use of paraCEST was illustrated by Toth et al. whereby action of $\beta \mathrm{Gal}$ converted a masked carbamate to an
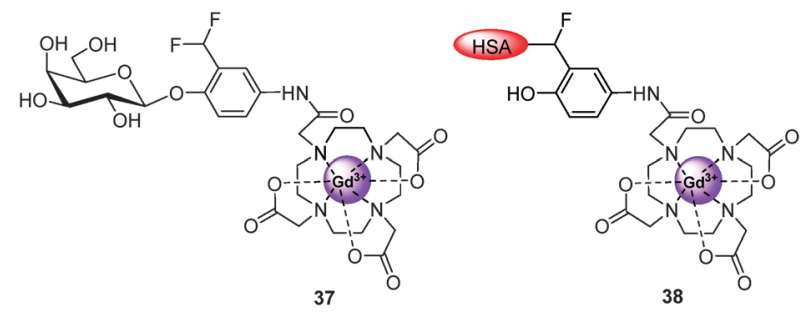

Fig. $16 \beta$ Gal MRI contrast agent. 
amine with concomitant changes in the paraCEST properties of a $\mathrm{Yb}$ (III)-chelating unit due to the different exchange rates and chemical shifts of the carbamate and amine protons. ${ }^{146}$ This approach allowed the monitoring of the kinetics of enzyme catalysed bond cleavage.

\section{Other approaches}

\subsection{Gels}

The applications of biomaterials for sensing of enzyme activity using "smart", stimuli-responsive materials and synthetic supramolecular pores has been reported for various enzymes. ${ }^{147,148}$ Gels contain a large amount of immobilized solvent and are therefore regarded as an intermediate state between a dry and wet system. Hydrogels typically consist of chemically or physically cross-linked polymers and are heavily investigated for application as "soft" materials. ${ }^{149-151}$ Hamachi and co-workers reported a novel hydrogelator comprised of a glycosylated amino acid ester scaffold which spontaneously formed a gel and exhibited unique amphilicity. This semi-wet structure allows for an aqueous medium for the inclusion of native-state enzymes whilst having hydrophobic domains for monitoring the enzymatic transformations, allowing a convenient sensing domain to monitor glycosidases and various other hydrolytic enzymes. ${ }^{149,152,153}$ Subsequently, Hamachi reported a colourimetric hydrogel which showed a distinguishable naked eye colour change in response to the presence glycosidases. ${ }^{154}$ Unique, bola-amphilic glycolipids 39 self-assembled to form a supramolecular hydrogel which exhibited a yellow-to-orange colour change along with gel-to-sol transition when subjected to $\beta$ Glc, allowing for rapid detection of the enzyme (Fig. 17).

Maitra et al. reported a novel sensing of enzymes using a gelbased $\mathrm{Tb}$ (III) luminescence assay, obviating the need for chelation of the lanthanide ion by a multidentate ligand. ${ }^{155}$ Previous studies showed that 2,3-dihydroxynaphthalene (DHN) sensitization of lanthanides could be achieved using a rigid cholate gel matrix. ${ }^{156}$ This method was extended to produce "pro-sensitizer" 40 as a $\beta$ Glc substrate, which, upon action of an enzyme causes luminescence of the gel (Fig. 17). ${ }^{155}$ This principle was then later applied to generate functionalised vesicles by embedding $\mathrm{Tb}$ (III)-cholate aggregates into the membrane of unimellar 1,2-dioleoyl-sn-glycero3-phosphatidylcholine (DOPC) vesicles which act as luminescent probes for the enzymatic transformations of lipase and $\beta \mathrm{Glc} .^{157}$

\subsection{Nanoparticles}

Surface plasmon resonance (SPR) spectroscopy is a sensitive technique which is increasingly being used for sensor technology.



39



40
Fig. 17 Gel incorporated glycosidase substrates.
Gold nanoparticles (AuNPs) have inherent sensing abilities due to their interesting optical and electronic properties and they have served as a versatile platform for exploring many facets of sensor technology. AuNP-based colourimetric assays have been developed which probe the interactions between a recognition unit immobilized on the AuNP and an analyte. ${ }^{158-160}$ Many of these colourimetric assays rely on the ability of AuNPs to aggregate and the subsequent shift of the SPR band to higher wavelengths resulting in a visible colour change. ${ }^{161,162}$

Zhang and co-workers reported a colourimetric method for the detection of $\alpha$ Glc activity and inhibitor screening based on AuNPs. ${ }^{163}$ The method is based on the specific recognition between 1,4-phenylene diboronic acid (PDBA) and 4-aminophenyl$\alpha$-D-glucopyranoside (pAPG). Addition of the PDBA to the pAPG triggers extensive agglomeration of the AuNPs and colour change from red to blue with concomitant appearance of a new absorbance peak at $650 \mathrm{~nm}$ due to the interaction between the boronic acid and the glycan moiety. However, in the presence of $\alpha \mathrm{Glc}$, no aggregation or colour change is observed due to the cleavage of the glycosidic bond and the absence of binding interactions between PDBA and the free phenol group. This method was used to screen the activity of the well-known glucosidase inhibitors. A self-immolative approach was adopted by Kikuchi et al. who reported a AuNP assay for the detection of $\beta$ Gal and $\beta$ Glc and its application for glycosidase inhibitor screening (Fig. 18). ${ }^{164}$ They synthesised glycoside-masked lipoic acid derivatives 41 which undergo self-immolative elimination to produce primary amines upon cleavage of the glycosidic bond. Under physiological conditions, the charged ammonium groups electrostatically interact with neighbouring lipoate groups on neighbouring AuNPs and a successive shift in the SPR from $521 \mathrm{~nm}$ to $700 \mathrm{~nm}$ associated with AuNP aggregation was observed, accompanied by a colour change clearly visible to the naked eye. Furthermore, they demonstrated the utility of such a system by screening the well-known glycosidase inhibitors, D-galactal and castanospermine.

\subsection{Surface enhanced resonance Raman scattering (SERRS)}

SERRS is an alternative approach to fluorescence and is becoming a widely used methodology for bioanalysis. It produces characteristic bands and detailed fingerprint of the target without the need for tedious separations and can be carried out in aqueous solutions due to the weak scattering from water molecules. It is a sensitive technique allowing the detection of single molecules, overcoming the insensitivity associated with Raman spectroscopy. ${ }^{34,165,166}$ "Masked" enzyme substrates that are initially undetectable by SERRS until action by a hydrolytic enzyme allows for information-rich vibrational spectra to be produced which lend the technique favourably to identifying multiple components in a mixture. ${ }^{166}$

Moore et al. demonstrated that 8-hydroxy quinolinyl azo dye derivatives can serve as SERRS reporters for the detection of hydrolytic enzymes. ${ }^{167,168}$ They used a SERRS approach to simultaneously detect alkaline phosphatase substrate 42 and $\beta$ Gal substrate $\mathbf{4 3}$ by masking the 8-hydroxy group with an enzyme hydrolysable moiety reducing the surface enhancement of the Raman response (Fig. 19). The SERRS signal is then 

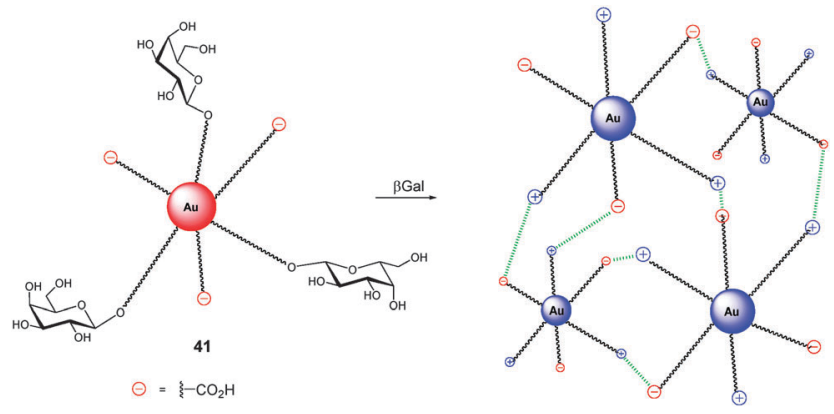

Fig. 18 AuNP glycosidase reporters.
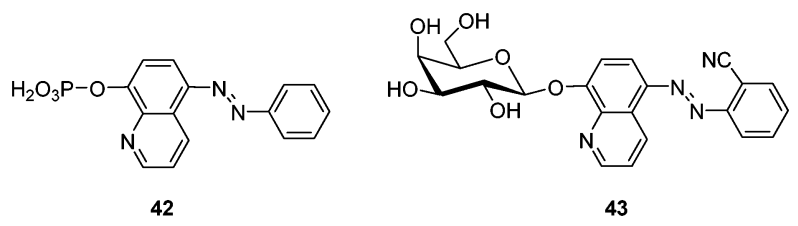

Fig. 19 Glycosidase SERRS reporters.

switched "on" following enzyme action with the emergence of each dye displaying distinct Raman bands allowing them to be differentiated.

\section{Conclusions}

The above account has clearly demonstrated the diversity of chemical substrates that have been developed for the detection of glycosidase enzymes. Although significant progress has been made, particularly in the field of NIR fluorophore development and application, there still remain several challenges to overcome prior to the emergence of a general strategy for glycosidase detection. As outlined in the introduction, due to the critical biological role of glycosidase enzymes in nature, there exists an exciting opportunity to develop probes suitable as tools for medical diagnostics and drug screening. While some preliminary examples of in vivo assays have been described above, significant further development is required in order to develop tools suitable for probing complex glycobiology processes. The ability to assay multiple glycosidase enzymes simultaneously using the same substrate coupled with advances in sensitivity for the detection of reporter molecules represents a major advance in the field. The development of efficient strategies to probe endo-glycosidases, without recourse to the use of multiple enzymes remains a significant challenge for the field. It is anticipated that the development of novel strategies for the detection of glycosidase enzymes will remain an active area of research in the future.

\section{Acknowledgements}

The authors would like to acknowledge the Irish Research Council (IRC) Embark Initiative, IRCSET for postgraduate studentships (to HMB) and Science Foundation Ireland (SFI) for Principle Investigation Award (SFI PI 2013).

\section{Notes and references}

1 R. Apweiler, H. Hermjakob and N. Sharon, Biochim. Biophys. Acta, Gen. Subj., 1999, 1473, 4.

2 A. Varki, Glycobiology, 1993, 3, 97.

3 P. M. Rudd, T. Elliott, P. Cresswell, I. A. Wilson and R. A. Dwek, Science, 2001, 291, 2370.

4 C. R. Bertozzi and L. L. Kiessling, Science, 2001, 291, 2357.

5 R. Wolfenden, X. Lu and G. Young, J. Am. Chem. Soc., 1998, 120, 6814 .

6 D. L. Zechel and S. G. Withers, Acc. Chem. Res., 2000, 33, 11.

7 G. J. Davies and M. L. Sinnott, Biochemistry, 2008, 30, 26.

8 P. M. Coutinho, E. Deleury and B. Henrissat, J. Appl. Glycosci., 2003, 50, 241.

9 D. E. Koshland, Jr., Biol. Rev. Cambridge Philos. Soc., 1953, 28, 416.

10 J. D. McCarter and S. G. Withers, Curr. Opin. Struct. Biol., 1994, 4, 885.

11 C. S. Rye and S. G. Withers, Curr. Opin. Chem. Biol., 2000, 4, 573.

12 K. A. Stubbs, Carbohydr. Res., 2014, 390, 9.

13 B. Henrissat and G. Davies, Curr. Opin. Struct. Biol., 1997, 7, 637.

14 V. Lombard, H. Golaconda Ramulu, E. Drula, P. M. Coutinho and B. Henrissat, Nucleic Acids Res., 2014, 42, D490.

15 P. Bojarova and V. Kren, Trends Biotechnol., 2009, 27, 199.

16 L. Plegt and R. J. Bino, Mol. Gen. Genet., 1989, 216, 321.

17 R. A. Jefferson, S. M. Burgess and D. Hirsh, Proc. Natl. Acad. Sci. U. S. A., 1986, 83, 8447.

18 G. A. Grabowski, S. Gatt and M. Horowitz, Crit. Rev. Biochem. Mol. Biol., 1990, 25, 385.

19 N. Gasparotto, R. Tomanin, A. C. Frigo, G. Niizawa, E. Pasquini, M. Blanco, M. A. Donati, J. Keutzer, F. Zacchello and M. Scarpa, Clin. Chim. Acta, 2009, 402, 38.

20 T. D. Butters, R. A. Dwek and F. M. Platt, Chem. Rev., 2000, 100, 4683.

21 K. Ohtsubo and J. D. Marth, Cell, 2006, 126, 855.

22 D. L. Meany and D. W. Chan, Clin. Proteomics, 2011, 8, 7.

23 H. G. Hers, Biochem. J., 1963, 86, 11.

24 D. Kalyani, K.-M. Lee, T.-S. Kim, J. Li, S. S. Dhiman, Y. C. Kang and J.-K. Lee, Fuel, 2013, 107, 815.

25 L. I. Willems, J. Jiang, K.-Y. Li, M. D. Witte, W. W. Kallemeijn, T. J. N. Beenakker, S. P. Schroeder, J. M. F. G. Aerts, G. A. van der Marel, J. D. C. Codee and H. S. Overkleeft, Chem. - Eur. J., 2014, 20, 10864.

26 K. H. Aamlid, G. Lee, B. V. Smith, A. C. Richardson and R. G. Price, Carbohydr. Res., 1990, 205, C5.

27 J. D. Perry, K. A. Morris, A. L. James, M. Oliver and F. K. Gould, J. Appl. Microbiol., 2007, 102, 410.

28 T. Tangkuaram, J. Q. Gerlach, Y. Xiang, A.-N. Kawde, Z. Dai, V. P. Bhavanandan, J. T. La Belle, W. Veerasai, L. Joshi and J. Wang, Analyst, 2006, 131, 889.

29 J. Kiernan, Biotech. Histochem., 2007, 82, 73.

30 J. Formanek, Angew. Chem., 1928, 41, 1133.

31 S. Boettcher and J. Thiem, Trends Carbohydr. Res., 2014, 6, 1.

32 S. Böttcher and J. Thiem, Eur. J. Org. Chem., 2014, 564.

33 H. Arakawa, A. Tsuji and M. Maeda, J. Biolumin. Chemilumin., 1998, 13, 349.

34 C. Ruan, W. Wang and B. Gu, Anal. Chem., 2006, 78, 3379.

35 K. Kiyose, H. Kojima and T. Nagano, Chem. - Asian J., 2008, 3, 506.

36 X.-M. Peng, G. L. V. Damu and C.-H. Zhou, Curr. Pharm. Des., 2013, 19, 3884 .

37 B. D. Wagner, Molecules, 2009, 14, 210.

38 D. Ray and P. K. Bharadwaj, Inorg. Chem., 2008, 47, 2252.

39 J. Li, C.-F. Zhang, Z.-Z. Ming, G.-F. Hao, W.-C. Yang and G.-F. Yang, Tetrahedron, 2013, 69, 4743.

40 Q. Sun, J. Li, W.-N. Liu, Q.-J. Dong, W.-C. Yang and G.-F. Yang, Anal. Chem., 2013, 85, 11304.

41 J. Li, C.-F. Zhang, S.-H. Yang, W.-C. Yang and G.-F. Yang, Anal. Chem., 2014, 86, 3037.

42 R. S. Agnes, F. Jernigan, J. R. Shell, V. Sharma and D. S. Lawrence, J. Am. Chem. Soc., 2010, 132, 6075.

43 D. N. Kramer and G. G. Guilbault, Anal. Chem., 1964, 36, 1662.

44 W. R. Sherman and E. Robins, Carbohydr. Res., 1968, 7, 184.

45 C. R. Drake, D. C. Miller and E. F. Jones, Curr. Org. Synth., 2011, 8, 498.

46 J. A. Mead, J. N. Smith and R. T. Williams, Biochem. J., 1954, 58, xxxv. 
47 J. A. R. Mead, J. N. Smith and R. T. Williams, Biochem. J., 1955, 61, 569. 48 D. Robinson, Biochem. J., 1956, 63, 39.

49 D. Robinson, Comp. Biochem. Physiol., 1964, 12, 95.

50 T. G. Warner and J. S. O'Brien, Biochemistry, 1979, 18, 2783.

51 M. Engstler, J. W. Talhouk, R. E. Smith and R. Schauer, Anal. Biochem., 1997, 250, 176.

52 D. Mangan, B. V. McCleary, A. Liadova, R. Ivory and N. McCormack, Carbohydr. Res., 2014, 395, 47.

53 O. Motabar, Z.-D. Shi, E. Goldin, K. Liu, N. Southall, E. Sidransky, C. P. Austin, G. L. Griffiths and W. Zheng, Anal. Biochem., 2009, 390, 79.

54 Z.-D. Shi, O. Motabar, E. Goldin, K. Liu, N. Southall, E. Sidransky, C. P. Austin, G. L. Griffiths and W. Zheng, Anal. Bioanal. Chem., 2009, 394, 1903.

55 W. H. Porter, C. D. Jennings, Jr. and H. D. Wilson, Clin. Chem., 1986, 32, 652 .

56 Y. Li, H. Wang, J. Li, J. Zheng, X. Xu and R. Yang, Anal. Chem., 2011, 83, 1268.

57 J. R. Lakowicz, Principles of Fluorescence Spectroscopy, Plenum Press, 1983.

58 K. E. Sapsford, L. Berti and I. L. Medintz, Angew. Chem., Int. Ed., 2006, 45, 4562.

59 L. Yuan, W. Lin, K. Zheng and S. Zhu, Acc. Chem. Res., 2013, 46, 1462.

60 H. Takakusa, K. Kikuchi, Y. Urano, H. Kojima and T. Nagano, Chem. - Eur. J., 2003, 9, 1479.

61 H. Hinou and S.-I. Nishimura, Curr. Top. Med. Chem., 2009, 9, 106.

62 A. Prasanna de Silva, T. S. Moody and G. D. Wright, Analyst, 2009, 134, 2385.

63 J. F. Callan, A. P. de Silva and D. C. Magri, Tetrahedron, 2005, 61, 8551.

64 T. Komatsu, K. Kikuchi, H. Takakusa, K. Hanaoka, T. Ueno, M. Kamiya, Y. Urano and T. Nagano, J. Am. Chem. Soc., 2006, 128, 15946.

65 G.-Y. Yang, C. Li, M. Fischer, C. W. Cairo, Y. Feng and S. G. Withers, Angew. Chem., Int. Ed., 2015, 54, 5389.

66 S. Park and I. Shin, Org. Lett., 2007, 9, 619.

67 E. Pershagen, J. Nordholm and K. E. Borbas, J. Am. Chem. Soc., 2012, 134, 9832.

68 E. Pershagen and K. E. Borbas, Angew. Chem., Int. Ed., 2015, 54, 1787.

69 X. Chen, T. Pradhan, F. Wang, J. S. Kim and J. Yoon, Chem. Rev., 2012, 112, 1910.

70 C. A. Parker and W. T. Rees, Analyst, 1960, 85, 587.

71 B. Rotman, J. A. Zderic and M. Edelstein, Proc. Natl. Acad. Sci. U. S. A., 1963, 50, 1.

72 G. P. Nolan, S. Fiering, J. F. Nicolas and L. A. Herzenberg, Proc. Natl. Acad. Sci. U. S. A., 1988, 85, 2603.

73 V. A. Rakhmanova and R. C. Macdonald, Anal. Biochem., 1998, 257, 234.

74 Z. Huang, Biochemistry, 1991, 30, 8530.

75 K. Kalidasan, Y. Su, X. Wu, S.-Q. Yao and M. Uttamchandani, Chem. Commun., 2013, 49, 7237.

76 T. Miura, Y. Urano, K. Tanaka, T. Nagano, K. Ohkubo and S. Fukuzumi, J. Am. Chem. Soc., 2003, 125, 8666.

77 Y. Urano, M. Kamiya, K. Kanda, T. Ueno, K. Hirose and T. Nagano, J. Am. Chem. Soc., 2005, 127, 4888.

78 L. Lindqvist and G. W. Lundeen, J. Chem. Phys., 1966, 44, 1711.

79 M. Kamiya, H. Kobayashi, Y. Hama, Y. Koyama, M. Bernardo, T. Nagano, P. L. Choyke and Y. Urano, J. Am. Chem. Soc., 2007, 129, 3918.

80 T. Egawa, Y. Koide, K. Hanaoka, T. Komatsu, T. Terai and T. Nagano, Chem. Commun., 2011, 47, 4162.

81 M. Fu, Y. Xiao, X. Qian, D. Zhao and Y. Xu, Chem. Commun., 2008, 1780.

82 S. Yamaguchi and K. Tamao, J. Chem. Soc., Dalton Trans., 1998, 3693.

83 Y. Kushida, T. Nagano and K. Hanaoka, Analyst, 2015, 140, 685.

84 M. Beija, C. A. M. Afonso and J. M. G. Martinho, Chem. Soc. Rev., 2009, 38, 2410.

85 H. N. Kim, M. H. Lee, H. J. Kim, J. S. Kim and J. Yoon, Chem. Soc. Rev., 2008, 37, 1465.

86 M. Kamiya, D. Asanuma, E. Kuranaga, A. Takeishi, M. Sakabe, M. Miura, T. Nagano and Y. Urano, J. Am. Chem. Soc., 2011, 133, 12960.

87 J. E. Whitaker, R. P. Haugland, D. Ryan, P. C. Hewitt, R. P. Haugland and F. G. Prendergast, Anal. Biochem., 1992, 207, 267.

88 T. Peng and D. Yang, Org. Lett., 2010, 12, 496.

89 Y. Koide, Y. Urano, K. Hanaoka, T. Terai and T. Nagano, ACS Chem. Biol., 2011, 6, 600 .
90 Y. Koide, Y. Urano, K. Hanaoka, W. Piao, M. Kusakabe, N. Saito, T. Terai, T. Okabe and T. Nagano, J. Am. Chem. Soc., 2012, 134, 5029.

91 T. Egawa, K. Hanaoka, Y. Koide, S. Ujita, N. Takahashi, Y. Ikegaya, N. Matsuki, T. Terai, T. Ueno, T. Komatsu and T. Nagano, J. Am. Chem. Soc., 2011, 133, 14157.

92 Y. Koide, Y. Urano, A. Yatsushige, K. Hanaoka, T. Terai and T. Nagano, J. Am. Chem. Soc., 2009, 131, 6058.

93 T. Yogo, Y. Urano, M. Kamiya, K. Sano and T. Nagano, Bioorg. Med. Chem. Lett., 2010, 20, 4320.

94 M. R. Detty, P. N. Prasad, D. J. Donnelly, T. Ohulchanskyy, S. L. Gibson and R. Hilf, Bioorg. Med. Chem., 2004, 12, 2537.

95 Y. Ichikawa, M. Kamiya, F. Obata, M. Miura, T. Terai, T. Komatsu, T. Ueno, K. Hanaoka, T. Nagano and Y. Urano, Angew. Chem., Int. Ed., 2014, 53, 6772.

96 M. Kamiya, D. Asanuma, E. Kuranaga, A. Takeishi, M. Sakabe, M. Miura, T. Nagano and Y. Urano, J. Am. Chem. Soc., 2011, 133, 12960.

97 M. Sakabe, D. Asanuma, M. Kamiya, R. J. Iwatate, K. Hanaoka, T. Terai, T. Nagano and Y. Urano, J. Am. Chem. Soc., 2012, 135, 409.

98 J.-A. Richard, M. Massonneau, P.-Y. Renard and A. Romieu, Org. Lett., 2008, 10, 4175.

99 A. Toutchkine, D.-V. Nguyen and K. M. Hahn, Org. Lett., 2007, 9, 2775.

100 R. Weissleder and V. Ntziachristos, Nat. Med., 2003, 9, 123.

101 J. V. Frangioni, Curr. Opin. Chem. Biol., 2003, 7, 626.

102 C.-H. Tung, Q. Zeng, K. Shah, D.-E. Kim, D. Schellingerhout and R. Weissleder, Cancer Res., 2004, 64, 1579.

103 H. Gong, B. Zhang, G. Little, J. Kovar, H. Chen, W. Xie, A. SchutzGeschwender and D. M. Olive, Anal. Biochem., 2009, 386, 59.

104 N.-h. Ho, R. Weissleder and C.-H. Tung, Tetrahedron, 2006, 62, 578.

105 N.-H. Ho, R. Weissleder and C.-H. Tung, Bioorg. Med. Chem. Lett., 2006, 16, 2599.

106 N.-H. Ho, R. Weissleder and C.-H. Tung, ChemBioChem, 2007, 8, 560 .

107 N. Karton-Lifshin, E. Segal, L. Omer, M. Portnoy, R. Satchi-Fainaro and D. Shabat, J. Am. Chem. Soc., 2011, 133, 10960.

108 J. Han, M. S. Han and C.-H. Tung, Mol. BioSyst., 2013, 9, 3001.

109 L. Hu, Z. Yan and H. Xu, RSC Adv., 2013, 3, 7667.

110 D. Oushiki, H. Kojima, Y. Takahashi, T. Komatsu, T. Terai, K. Hanaoka, M. Nishikawa, Y. Takakura and T. Nagano, Anal. Chem., 2012, 84, 4404.

111 K. Awasthi and G. Nishimura, Photochem. Photobiol. Sci., 2011, 10, 461.

112 M. Y. Losytskyy, K. D. Volkova, V. B. Kovalska, I. E. Makovenko, Y. L. Slominskii, O. I. Tolmachev and S. M. Yarmoluk, J. Fluoresc., 2005, 15, 849.

113 A. K. Yadav, D. L. Shen, X. Shan, X. He, A. R. Kermode and D. J. Vocadlo, J. Am. Chem. Soc., 2015, 137, 1181.

114 M. D. Witte, W. W. Kallemeijn, J. Aten, K.-Y. Li, A. Strijland, W. E. Donker-Koopman, A. M. C. H. van den Nieuwendijk, B. Bleijlevens, G. Kramer, B. I. Florea, B. Hooibrink, C. E. M. Hollak, R. Ottenhoff, R. G. Boot, G. A. van der Marel, H. S. Overkleeft and J. M. F. G. Aerts, Nat. Chem. Biol., 2010, 6, 907.

115 I. Hemmilae and V. Laitala, J. Fluoresc., 2005, 15, 529.

116 J. P. Leonard, C. B. Nolan, F. Stomeo and T. Gunnlaugsson, Top. Curr. Chem., 2007, 281, 1.

117 L. Armelao, S. Quici, F. Barigelletti, G. Accorsi, G. Bottaro, M. Cavazzini and E. Tondello, Coord. Chem. Rev., 2010, 254, 487.

118 V. V. Zherdeva and A. P. Savitsky, Biochemistry, 2012, 77, 1553.

119 D. Parker, Coord. Chem. Rev., 2000, 205, 109.

120 S. Faulkner, S. J. A. Pope and B. P. Burton-Pye, Appl. Spectrosc. Rev., $2005,40,1$.

121 S. I. Weissman, J. Chem. Phys., 1942, 10, 214.

122 D. Parker and J. A. G. Williams, J. Chem. Soc., Dalton Trans., 1996, 3613.

123 D. E. Barry, J. A. Kitchen, M. Albrecht, S. Faulkner and T. Gunnlaugsson, Langmuir, 2013, 29, 11506.

124 J. A. Kitchen, D. E. Barry, L. Mercs, M. Albrecht, R. D. Peacock and T. Gunnlaugsson, Angew. Chem., Int. Ed., 2012, 51, 704.

125 S. Comby, S. A. Tuck, L. K. Truman, O. Kotova and T. Gunnlaugsson, Inorg. Chem., 2012, 51, 10158.

126 B. K. McMahon and T. Gunnlaugsson, Tetrahedron Lett., 2010, $51,5406$.

127 O. Reany, T. Gunnlaugsson and D. Parker, J. Chem. Soc., Perkin Trans. 2, 2000, 1819.

128 C. M. Gomes dos Santos and T. Gunnlaugsson, Dalton Trans., 2009, 4712 . 
129 J. Massue, S. J. Quinn and T. Gunnlaugsson, J. Am. Chem. Soc., 2008, 130, 6900.

130 S. C. M. G. dos, P. B. Fernandez, S. E. Plush, J. P. Leonard and T. Gunnlaugsson, Chem. Commun., 2007, 3389.

131 G. Pintacuda, M. John, X.-C. Su and G. Otting, Acc. Chem. Res., 2007, 40, 206.

132 A. Canales, A. Mallagaray, M. A. Berbis, A. Navarro-Vazquez, G. Dominguez, F. J. Canada, S. Andre, H.-J. Gabius, J. Perez-Castells and J. Jimenez-Barbero, J. Am. Chem. Soc., 2014, 136, 8011.

133 C. M. Spangler, C. Spangler and M. Schaerling, Ann. N. Y. Acad. Sci., 2008, 1130, 138.

134 B. K. McMahon and T. Gunnlaugsson, J. Am. Chem. Soc., 2012, 134, 10725 .

135 K. E. Borbas and J. I. Bruce, Org. Biomol. Chem., 2007, 5, 2274.

136 R. A. Moats, S. E. Fraser and T. J. Meade, Angew. Chem., Int. Ed. Engl., 1997, 36, 726.

137 A. Y. Louie, M. M. Huber, E. T. Ahrens, U. Rothbacher, R. Moats, R. E. Jacobs, S. E. Fraser and T. J. Meade, Nat. Biotechnol., 2000, 18, 321.

138 L. M. Urbanczyk-Pearson, F. J. Femia, J. Smith, G. Parigi, J. A. Duimstra, A. L. Eckermann, C. Luchinat and T. J. Meade, Inorg. Chem., 2008, 47, 56.

139 J. A. Duimstra, F. J. Femia and T. J. Meade, J. Am. Chem. Soc., 2005, $127,12847$.

140 K. Hanaoka, K. Kikuchi, T. Terai, T. Komatsu and T. Nagano, Chem. - Eur. J., 2008, 14, 987.

141 Y.-T. Chang, C.-M. Cheng, Y.-Z. Su, W.-T. Lee, J.-S. Hsu, G.-C. Liu, T.-L. Cheng and Y.-M. Wang, Bioconjugate Chem., 2007, 18, 1716.

142 A. Keliris, T. Ziegler, R. Mishra, R. Pohmann, M. G. Sauer, K. Ugurbil and J. Engelmann, Bioorg. Med. Chem., 2011, 19, 2529.

143 F. Arena, J. B. Singh, E. Gianolio, R. Stefania and S. Aime, Bioconjugate Chem., 2011, 22, 2625.

144 J. W. Chen, W. Pham, R. Weissleder and A. Bogdanov, Jr., Magn. Reson. Med., 2004, 52, 1021.

145 M. Querol, D. G. Bennett, C. Sotak, H. W. Kang and A. Bogdanov, Jr., ChemBioChem, 2007, 8, 1637.
146 T. Chauvin, P. Durand, M. Bernier, H. Meudal, B.-T. Doan, F. Noury, B. Badet, J.-C. Beloeil and E. Toth, Angew. Chem., Int. Ed., 2008, 47, 4370.

147 G. Das, P. Talukdar and S. Matile, Science, 2002, 298, 1600.

148 T. Takeuchi and S. Matile, Chem. Commun., 2013, 49, 19.

149 S. Kiyonaka, K. Sada, I. Yoshimura, S. Shinkai, N. Kato and I. Hamachi, Nat. Mater., 2004, 3, 58.

150 K. Y. Lee and D. J. Mooney, Chem. Rev., 2001, 101, 1869.

151 R. Pelton, Adv. Colloid Interface Sci., 2000, 85, 1.

152 S. Kiyonaka, S. Shinkai and I. Hamachi, Chem. - Eur. J., 2003, 9, 976.

153 S.-i. Tamaru, S. Kiyonaka and I. Hamachi, Chem. - Eur. J., 2005, 11, 7294.

154 R. Ochi, K. Kurotani, M. Ikeda, S. Kiyonaka and I. Hamachi, Chem. Commun., 2013, 49, 2115.

155 S. Bhowmik and U. Maitra, Chem. Commun., 2012, 48, 4624.

156 S. Bhowmik, S. Banerjee and U. Maitra, Chem. Commun., 2010, 46, 8642.

157 S. Balk, U. Maitra and B. Koenig, Chem. Commun., 2014, 50, 7852.

158 R. V. Ulijn, J. Mater. Chem., 2006, 16, 2217.

159 G. Song, C. Chen, J. Ren and X. Qu, ACS Nano, 2009, 3, 1183.

160 J. Deng, Q. Jiang, Y. Wang, L. Yang, P. Yu and L. Mao, Anal. Chem., 2013, 85, 9409.

161 S. K. Ghosh and T. Pal, Chem. Rev., 2007, 107, 4797.

162 J. J. Storhoff, A. A. Lazarides, R. C. Mucic, C. A. Mirkin, R. L. Letsinger and G. C. Schatz, J. Am. Chem. Soc., 2000, 122, 4640. 163 J. Zhang, Y. Liu, J. Lv and G. Li, Nano Res., 2014, 1.

164 Z. Zeng, S. Mizukami and K. Kikuchi, Anal. Chem., 2012, 84, 9089.

165 B. D. Moore, L. Stevenson, A. Watt, S. Flitsch, N. J. Turner, C. Cassidy and D. Graham, Nat. Biotechnol., 2004, 22, 1133.

166 C. L. Haynes, A. D. McFarland and R. P. Van Duyne, Anal. Chem., 2005, 77, 338A.

167 A. Ingram, B. D. Moore and D. Graham, Bioorg. Med. Chem. Lett., 2009, 19, 1569.

168 A. Ingram, R. J. Stokes, J. Redden, K. Gibson, B. Moore, K. Faulds and D. Graham, Anal. Chem., 2007, 79, 8578. 